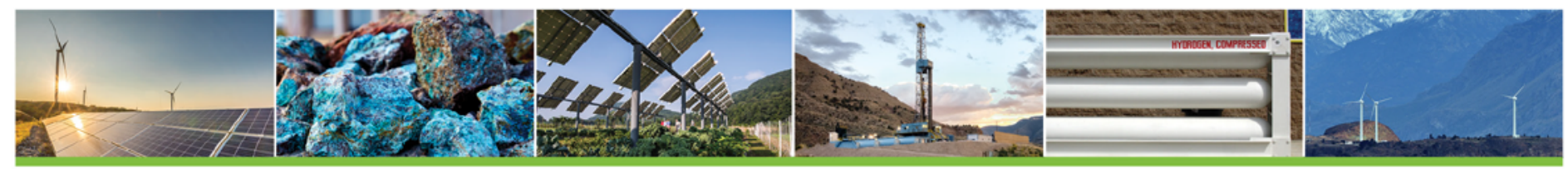

\title{
Opportunities for Industry to Provide Flexibility While Increasing Profitability
}

David J. Garfield, Paige N. Jadun National Renewable Energy Laboratory

Shannon Hwang

Massachusetts Institute of Technology

Mark O'Malley

University College Dublin

Mark F. Ruth

National Renewable Energy Laboratory, Joint Institute for Strategic Energy Analysis

Technical Report

NREL/TP-6A50-75784

September 2021

Contract No. DE-AC36-08GO28308 


\section{Opportunities for Industry to Provide Flexibility While Increasing Profitability}

David J. Garfield, Paige N. Jadun

National Renewable Energy Laboratory

Shannon Hwang

Massachusetts Institute of Technology

Mark O'Malley

University College Dublin

Mark F. Ruth

National Renewable Energy Laboratory, Joint Institute for Strategic Energy Analysis

The Joint Institute for Strategic Energy Analysis 15013 Denver West Parkway Golden, CO 80401 www.jisea.org
The Joint Institute for Strategic Energy Analysis is operated by the Alliance for Sustainable Energy, LLC, on behalf of the U.S. Department of Energy's National Renewable Energy Laboratory, the University of Colorado-Boulder, the Colorado School of Mines, the Colorado State University, the Massachusetts Institute of Technology, and Stanford University.

JISEA $^{\circledR}$ and all JISEA-based marks are trademarks or registered trademarks of the Alliance for Sustainable Energy, LLC.

Technical Report

NREL/TP-6A50-75784

September 2021

Contract No. DE-AC36-08GO28308 


\section{NOTICE}

This work was authored in part by the National Renewable Energy Laboratory (NREL), operated by Alliance for Sustainable Energy, LLC, for the U.S. Department of Energy (DOE) under Contract No. DE-AC36-08G028308. Funding provided by the Joint Institute for Strategic Energy Analysis through a Cooperative Research and Development Agreement between NREL and GE. Additionally, S.H. was funded through a DOE Summer Undergraduate Laboratory Internship at NREL while she performed the work for this report. The authors are grateful to Jill Engel-Cox, Steven Freilich, Deborah Lew, and Eduardo Ibanez for helpful discussions, and GE for their perspective and advice (NREL did not ask GE to endorse the study findings and recommendations). The views expressed herein do not necessarily represent the views of the DOE, the U.S. Government, or sponsors.

This report is available at no cost from the National Renewable Energy Laboratory (NREL) at www.nrel.gov/publications.

U.S. Department of Energy (DOE) reports produced after 1991 and a growing number of pre-1991 documents are available free via www.OSTI.gov. 


\begin{abstract}
As the share from variable renewable generation continues to grow, supply and demand flexibility will be needed to ensure a functioning electricity system. Industrial manufacturing currently consumes a third of primary energy worldwide, and industrial electricity consumption is projected to grow as the global economy decarbonizes. Therefore, the ability of industry to flex demand poses an enticing opportunity to enable grid flexibility. However, large capital outlays prevent industry from voluntarily altering demand. In this report, we show that as battery costs continue to fall, industry will soon be able to profitably alter demand in accordance with electricity price variations. Focusing on two established industries - chlor-alkali and electric arc furnaces (EAFs) - and two industries with large future potential - methane pyrolysis and atmospheric $\mathrm{CO}_{2}$ capture-we used a linear program optimization to assess the techno-economic feasibility of flexible industrial demand across both historical and future-looking wholesale dayahead marginal prices for the Electricity Reliability Council of Texas (ERCOT). We found positive net present values (NPVs) from $\$ 400,000$ to $\$ 50$ million using projected 2050 battery prices for industrial behind-the-meter batteries, using only arbitrage as a source of value. These results indicate that, in the near future, profit-seeking industrial players could help stabilize a high-renewables grid.
\end{abstract}




\section{List of Acronyms}

\section{CAPEX}

$\mathrm{CO}_{2}$

DAC

DOE

EAF

ECU

ERCOT

$\mathrm{H}_{2}$

Li-ion

LMP

NPV

NREL

$\mathrm{O}_{2}$

OPEX

ReEDS capital expenditure

carbon dioxide

direct air capture

U.S. Department of Energy

electric arc furnace

electrochemical unit

Electricity Reliability Council of Texas

hydrogen

lithium-ion

locational marginal price

net present value

National Renewable Energy Laboratory

oxygen

operating expenses

Regional Energy Deployment System 


\section{Table of Contents}

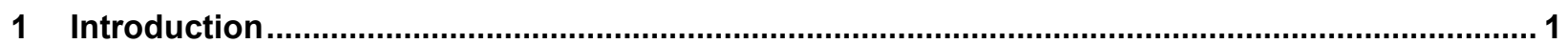

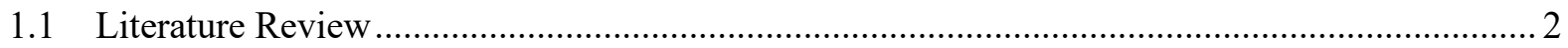

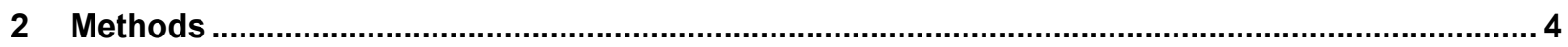

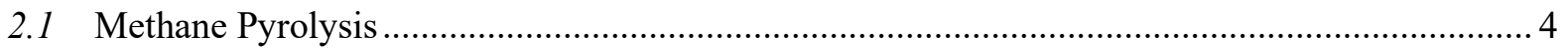

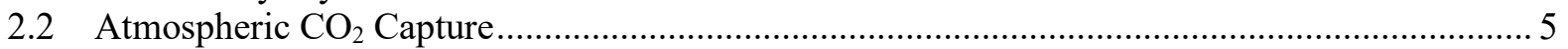

2.3 Economic Feasibility of Negative Control Without Paired Storage.............................................. 6

2.4 Economic Feasibility of Negative Control With Paired Storage ................................................. 8

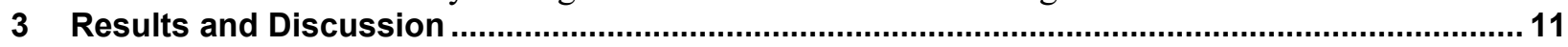

3.1 Economic Feasibility of Negative Control Without Paired Storage.......................................... 11

3.2 Economic Feasibility of Negative Control With Paired Storage ............................................... 11

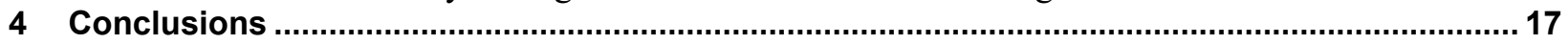

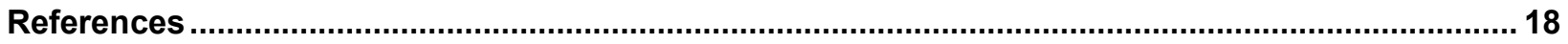

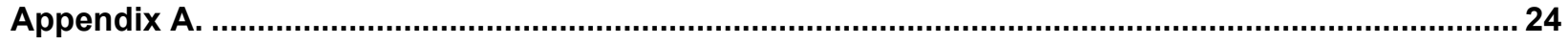

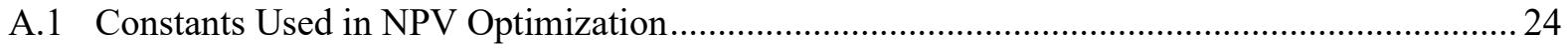

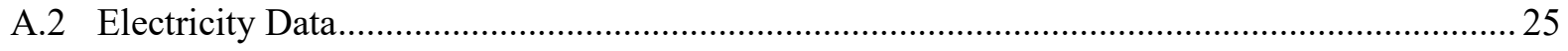

A.3 Calculation for Minimum Selling Cost (MSC) …................................................................. 25

A.4 Optimal Battery Sizes Found for 2050 Low and Medium Battery Cost Scenarios..................... 26 


\section{List of Figures}

Figure 1. Production cost normalized to the unit selling price for each respective industry ..................... 6

Figure 2. Battery NPV sensitivities to projected battery costs............................................................ 13

Figure 3. Load profiles chlor-alkali process with no battery vs. a paired optimally sized battery ............ 15

Figure A2- 1. Price duration curves for the electricity price data sets used (2019 and 2050) .................. 25

Figure A2- 2. Zonal load vs. nodal LMP for the Judkins node in ERCOT West Load Zone, 2019 .......... 25

Figure A4- 1. NPVs across different battery energy and power capacities ............................................ 27

Figure A4- 2. NPVs across different battery energy and power capacities ............................................ 28

\section{List of Tables}

Table 1. Fixed Process Parameters Used to Model Industrial Energy Use............................................... 5

Table 2. Modeled NPV Changes in Adopting Negative Control Strategies vs. No Negative Control ....... 11

Table 3. Optimal NPVs in Millions of Dollars Across Years and Battery Prices..................................... 11

Table 4. Comparisons of First-Year Behavior When Pairing the Considered Process With an Optimally

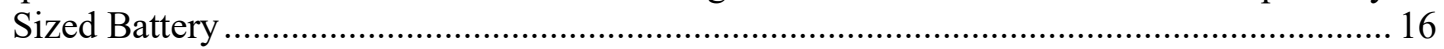

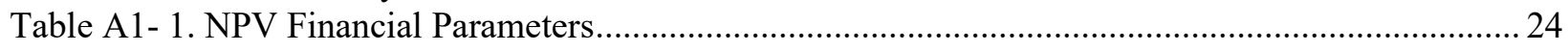

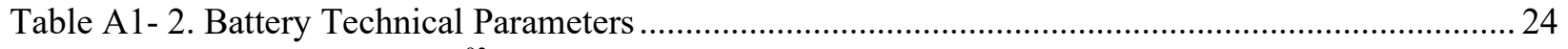

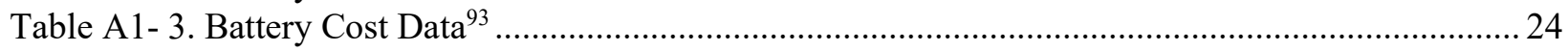

Table A4- 1. Optimal Battery MWh and MW Capacities for 2050 Low and Medium Battery Cost ......... 26 


\section{Introduction}

Deployment of wind, solar, and other variable renewable energy resources continues to grow rapidly as costs become increasingly competitive. ${ }^{1,2}$ However, the intermittent and timecorrelated nature of variable renewable resources combined with limited flexibility due to commitment and dispatch constraints of the power system, can result in supply and demand imbalances in electricity markets with high wind and solar penetration, manifesting as dramatic electricity price fluctuations, curtailment of renewable energy generation, and potential grid instability. ${ }^{3}$ Highly flexible power systems will therefore be needed to handle these fluctuations in renewable generation and effectively integrate large percentages of variable renewable generation. ${ }^{4}$

Adding flexibility to industrial energy demand represents one potential avenue to greatly increasing adaptability and robustness of the grid, ${ }^{5,6}$ especially with the prospect of electrifying industrial process heat. ${ }^{7,8}$ Industry currently consumes a third of total primary energy across the United States and worldwide. ${ }^{9,10}$ While the vast majority of this energy is currently derived from combusting fossil fuels, efforts to decarbonize industry point to electrification as a possible avenue to curb emissions. ${ }^{7,11}$ This shift would represent a massive increase in electricity demand on the grid, potentially adding the equivalent of $60 \%$ of today's total load, ${ }^{11}$ and a tremendous opportunity to add grid flexibility.

Industrial processes can add flexibility through demand response, ramping down industrial load and production intensity according to grid demand or capacity prices. ${ }^{12}$ However, industry typically does not participate in demand response due to regulatory, knowledge, and financial barriers, ${ }^{12}$ as well as a temporal mismatch between operating and energy purchase decisions. In addition, many industrial customers today buy electricity via long-term fixed-price contracts at low rates, further diminishing the appeal of participating in demand response. ${ }^{13} \mathrm{We}$ assume in this study that industrial customers experience dynamic wholesale pricing that accurately signals grid demand and supply. ${ }^{14}$

Alternatively, industries can add demand flexibility by incorporating energy storage on-site. The addition of storage effectively circumvents the barriers to other modes of demand flexibility by enabling electricity price arbitrage: purchasing and storing electricity at low-cost hours and using it to power loads when electricity prices are high. ${ }^{15}$ This arbitrage behavior shifts electricity demand from periods of high electricity prices (presumably low renewable supply periods) to periods with lower electricity prices (presumably high renewable supply periods) while keeping industrial production at full capacity. As the cost of energy storage technologies such as lithiumion (Li-ion) batteries decline, they are becoming attractive across a wide swath of applications. $^{16,17}$

Siting these batteries on-site behind-the-meter presents several key benefits to the industrial customer versus siting them elsewhere on the system. Key existing assets such as substation equipment and the land itself can serve both the plant and battery when sited on-site. Regulatory look-through is limited in storage systems that only purchase electricity ${ }^{18,19}$ (satisfy a load) rather than those that both buy and sell electricity. ${ }^{20}$ An on-site battery or other energy storage system 
also potentially adds resiliency to an industrial facility to reduce expensive interruptions by unexpected power outages.

Besides arbitrage, battery systems can participate in revenue streams such as demand charge reduction, primary control reserve, ${ }^{21}$ and capacity deferral. ${ }^{22}$ Some have found that these alternative revenue streams may be more profitable than arbitrage ${ }^{23}$ and that combining multiple revenue streams may be necessary to render battery systems profitable. ${ }^{11,12}$ However, compensation for ancillary services, demand charge reduction, and capacity payments are highly dependent on policy and market structure that may change as the electricity grid transforms to incorporate high percentages of renewables. ${ }^{24,25,26}$

This work explores the current and future economic potential for adding demand flexibility to industrial processes with and without paired on-site storage. We begin by examining the ideal characteristics and minimum reimbursement an industrial plant would need to receive for it to willingly participate as negative control energy for the grid. Here, negative control refers to the ramping up of electricity loads to meet excess electricity supplies on the grid. We then develop a price-taker linear optimization model that considers battery power, energy, and degradation to explore the economic value of energy arbitrage in the day-ahead wholesale electricity market. We model the operation of batteries paired with four energy-intensive industries: chlor-alkali and electric arc furnaces (EAFs), which are established electricity-intensive industries, ${ }^{27-30}$ and methane pyrolysis and direct air capture (DAC) of carbon dioxide $\left(\mathrm{CO}_{2}\right)$, which have future growth and electrification potential. ${ }^{31-34}$ For these industries, we estimated optimal battery net present values (NPVs) using historical 2019 and simulated 2050 ERCOT electricity prices along with corresponding battery prices for the respective years. This analysis implicitly assumes that batteries are not yet widespread enough to unprofitably dampen electricity price fluctuations. As such, this work models the economic benefits that an early entrant into industrial behind-themeter storage would experience and does not consider the wide-scale grid impact of incorporating such storage.

\subsection{Literature Review}

Studies have examined traditional demand response from industry as a means of both positive ${ }^{12}$ and negative control energy. ${ }^{35}$ While many of these studies estimated the magnitude of demand response potential ${ }^{12,36}$ or grid-perspective benefits, ${ }^{37}$ few analyzed whether individual profitmotivated industrial players would pursue them. ${ }^{35,38}$ In practice, the potential for industrial demand response - both positive and negative control energy - faces barriers such as inflexible loads, negative impacts on downstream processes, and the need to recoup high capital expenditures. ${ }^{12,13,35,39}$

A number of studies have examined the potential and economics of demand response for the chlor-alkali industry specifically. ${ }^{28,36,40,41}$ Otashu et al. found that chlor-alkali process loads can nimbly adjust (on a 15 minute timescale) and that participating in demand response could result in process cost savings, but did not evaluate whether this resulted in overall profit for the plant operator. ${ }^{36}$ Paulus et al. found that chlor-alkali facilities in Germany could significantly increase demand response in the country, but the high opportunity cost of shedding process load rendered positive control financially prohibitive. ${ }^{40}$ They further found that the potential for chlor-alkali to act as negative control energy is significantly less than for positive control due to the high utilization level of existing facilities, therefore limiting the amount of negative reserve 
capacity. ${ }^{40}$ Others have investigated cost-saving strategies that shift chlor-alkali between different modes of operation, maintaining a steady output stream while providing both positive and negative energy control. ${ }^{42,43}$ However, this switching process also results in significant overhead and downtime needed to clean the plant, which necessitates overbuilding plant capacity to enable adequate demand response. ${ }^{42}$

Similarly, studies have examined the potential magnitude of demand response offered by EAF, ${ }^{44,45}$ as well as strategies for optimal furnace operation and potential electricity cost savings. ${ }^{46}$ Paulus et al. also examined the economic feasibility of demand response for EAF, and concluded that it was only feasible for positive control energy, and only with very high reserve energy prices $(>1000 € / \mathrm{MW})$ due to the high opportunity cost of interruptions. ${ }^{40}$

A number of studies ${ }^{15,23,47-55}$ have utilized a price-taker approach to estimate the value of energy storage participating in day-ahead, real-time, and/or ancillary service markets. These studies consider market arbitrage in addition to other revenue streams and use linear programs to formulate optimal charge and discharge schedules. However, as the estimated value of storage heavily depends on assumptions about storage technologies, electricity prices, and market characteristics that change with each study, authors differ on the relative profitability of different battery revenue streams and overall profitability of the considered battery systems. ${ }^{15}$

Studies have also estimated the value of battery storage specifically for industry. Braeuer et al. used a linear program to estimate the 2017 NPVs of installing battery systems in manufacturing plants for 50 different small- and medium-sized German enterprises, concluding that batteries could be profitable for some cases if multiple storage revenue streams were considered. ${ }^{39}$ Fisher et al. estimated emissions and economic payoffs from installing behind-the-meter storage for several hundred commercial and industrial buildings under 2013 market conditions. ${ }^{26}$ Zafirakis et al. analyzed the load management and arbitrage value of battery storage at a Greek industrial facility, but found that with existing electricity rate structures and battery prices, storage's value to the facility did not outweigh its capital investment. ${ }^{56}$ Brée et al. estimated potential profits from pairing batteries with chlor-alkali, but only considered a redox-flow battery across a limited range of sizes. ${ }^{57}$ Gholian et al. estimated profits for pairing a battery with a steel mill under various 2015 electricity pricing structures. ${ }^{58}$ All studies assessed battery value under historical battery price and electricity market conditions, and while Fisher et al. lists possible developments that would increase battery values in the future, they do not offer future-looking assessments of possible battery value for future industrial operators.

Several studies endogenously vary electricity price with large storage additions ${ }^{22,59-61}$ and quantify battery system value in terms of grid- or utility-level impact. However, larger-scale grid benefits may not directly translate into profit for a private storage owner. ${ }^{49,62}$ We used a pricetaker model for optimizing battery operation, and in doing so, assumed that battery operation did not change observed electricity prices. For the given node (Judkins, Electric Reliability Council of Texas [ERCOT] Load Zone West), we observed a very weak correlation between historical price and load (See Appendix). 


\section{Methods}

Before investigating the economic feasibilities of negative control strategies, we first chose specific industries to study based on the following criteria:

1. The process should currently have or have the potential in the future to consume very large amounts of energy.

2. The energy consumption should constitute a significant portion of the variable cost of production to create a large financial opportunity to the plant owner.

For the case of negative control without storage, an additional criterion must have been met:

3. Dynamic response to fluctuations in electricity supply must be technologically feasible for the respective process.

We examined processes that satisfy these three criteria, both with and without paired storage. When evaluating the ability for industry to act as negative control without storage, an additional attribute would be highly desirable: the required capital expenditure should be low, such that idle assets do not represent a significant financial burden. However, virtually all energy-intensive industrial processes require large amounts of physical capital to handle the large loads. This presents an inherent challenge when attempting to utilize industrial loads for negative control without paired energy storage.

The established industries we examined, chlor-alkali ${ }^{63,64,65,66}$ and EAF, ${ }^{67,68}$ have been described numerous times, so we will not do so here. However, because methane pyrolysis and DAC are nascent industries, we describe them briefly.

\subsection{Methane Pyrolysis}

Methane pyrolysis is the process of thermally separating $\mathrm{CH}_{4}$ into hydrogen gas and solid carbon. Though it is not yet a mature industry, in 2016 the company Monolith brought a Nebraska facility online ${ }^{69}$ to produce carbon black. Nonetheless, pyrolysis presents an opportunity to generate hydrogen from natural gas without emitting $\mathrm{CO}_{2}$, sometimes referred to as "turquoise" hydrogen, by heating methane in the absence of oxygen $\left(\mathrm{O}_{2}\right)$. Without $\mathrm{O}_{2}$, the methane cannot combust to $\mathrm{CO}_{2}$, and instead pyrolyzes to hydrogen $\left(\mathrm{H}_{2}\right)$ and solid carbon products. Much work has investigated molten-metal catalysts that can lower the activation temperature for this process. ${ }^{70,71}$ Yet the real appeal of methane pyrolysis comes from the solid carbon that the process produces. Without modification, the carbon forms an amorphous carbon powder that, in molten-metal reactors, floats to the top of the liquid metal and is continuously skimmed off. This amorphous carbon can be sold into the market for carbon black at roughly $\$ 1.35$ per kg. ${ }^{72}$ Currently, industry growth is limited by the size of the market for carbon black, which is not sufficient to absorb very large amounts from methane pyrolysis. One potential solid carbon market with tremendous growth potential is carbon fiber. In fact, the U.S. Department of Energy's (DOE's) Advanced Research Projects Agency, Energy recently awarded over \$14 million to four projects aiming to synthesize structural carbon fiber directly via methane pyrolysis to displace steel and cement. ${ }^{73}$ Carbon fiber currently has a market price of around $\$ 20 / \mathrm{kg}^{74}$ Despite this, we conservatively assume in this study that the carbon is sold at the market price for carbon black $(\$ 1.35 / \mathrm{kg})$, while the hydrogen is sold at $\$ 1 / \mathrm{kg}$, the current U.S. 
cost of production from steam methane reforming without carbon capture, ${ }^{69}$ and the two products are produced stoichiometrically as $1 \mathrm{~kg} \mathrm{H}_{2}$ for every $3 \mathrm{~kg}$ of C.

\subsection{Atmospheric $\mathrm{CO}_{2}$ Capture}

Atmospheric $\mathrm{CO}_{2}$ capture, another nascent industry, is projected to grow significantly in coming years to limit the effects of global warming. ${ }^{75-78}$ In the most generalized description of the process, ambient atmosphere is passed over a $\mathrm{CO}_{2}$-absorbing material (absorbent) that selectively binds the gas. This material is then typically heated to release the $\mathrm{CO}_{2}$, regenerating the absorbent while generating a stream of pure $\mathrm{CO}_{2}$ and consuming most of the energy required by the process. While this desorption step typically requires heating, we assume here this heating step can be electrified with no loss in efficiency or additional equipment costs. We assume generated revenue of $\$ 150 /$ ton $\mathrm{CO}_{2}\left(\mathrm{t}-\mathrm{CO}_{2}\right)$ unless otherwise stated, based on the projected future price for $\mathrm{DAC} \mathrm{CO}_{2}{ }^{79}$ This revenue could be generated from tax credits, carbon markets, businesses that buy $\mathrm{CO}_{2}$ for use or upcycling, or some combination therein.

Table 1 lists capital and operating parameters for the respective industries: the energy intensity per unit (EnergyIntensityper unit), nonenergy operating expenses (OPEX), capital expenditure (CAPEX), number of units said CAPEX can produce annually (Plant Size), and market price per

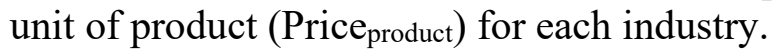

Table 1. Fixed Process Parameters Used to Model Industrial Energy Use

\begin{tabular}{|c|c|c|c|c|}
\hline Expenses & $\begin{array}{l}\text { Chlor- } \\
\text { Alkali } 65,66,80\end{array}$ & EAF $^{81}$ & $\begin{array}{l}\text { Methane } \\
\text { Pyrolysis }^{72}\end{array}$ & DAC $^{79}$ \\
\hline EnergyIntensityper unit & $\begin{array}{l}2.7 \\
\mathrm{MWh} / \text { ton } \\
\mathrm{ECU}\end{array}$ & $\begin{array}{l}550 \\
\mathrm{kWh} / \text { ton }^{29}\end{array}$ & $\begin{array}{l}16.1 \\
\text { kWh/unit }\end{array}$ & $\begin{array}{l}1.535 \\
\mathrm{MWh} / \mathrm{t}-\mathrm{CO}_{2}\end{array}$ \\
\hline OPEX & $\begin{array}{l}\$ 202.50 / \text { ton } \\
\text { ECU }\end{array}$ & $\$ 407 /$ ton & \$1.84/unit & $\$ 23 / \mathrm{t}-\mathrm{CO}_{2}$ \\
\hline CAPEX (\$ Million) & 270 & 252 & 11.4 & 779.5 \\
\hline Plant Size & $\begin{array}{l}182,000 \text { ton } \\
\text { ECU }\end{array}$ & $\begin{array}{l}2 \text { Million } \\
\text { ton }\end{array}$ & $\begin{array}{l}693,500 \\
\text { units }\end{array}$ & $\begin{array}{l}1 \text { Million t- } \\
\mathrm{CO}_{2}\end{array}$ \\
\hline Price product & $\begin{array}{l}\$ 968 / \text { ton } \\
\text { ECU }\end{array}$ & \$613/ton & \$7/unit & $\$ 150 / \mathrm{t}-\mathrm{CO}_{2}$ \\
\hline
\end{tabular}

Several assumptions were made in obtaining these numbers. One electrochemical unit (ECU) of the chlor-alkali process produces 1 ton $\mathrm{Cl}_{2}, 1.1$ tons $\mathrm{NaOH}$, and 0.03 ton $\mathrm{H}_{2}$, as dictated by stoichiometry. The energy intensity of chlor-alkali is taken for the membrane technology, but with an additional $0.3 \mathrm{MWh} /$ ton ECU to concentrate the caustic soda to $50 \%$ by weight. The market price of an ECU ton of chlor-alkali is taken as the average price from 2009 to 2017. ${ }^{65,66}$ For EAF steelmaking, the market price is taken as the average hot-rolled coil price for the Midwestern United States from 2014-2019. ${ }^{82}$ The authors also understand that the energy intensity for EAF utilizes a value that may be higher than the most advanced facilities, making the analysis conservative with regard to economic feasibility. In the case of methane pyrolysis, we assume that pyrolysis occurs via low-temperature plasma conversion at $700^{\circ} \mathrm{C},{ }^{72}$ and that one "unit" is equivalent to the stoichiometric decomposition of methane to solid carbon and 
hydrogen gas, where the solid carbon product can be sold for $\$ 1.35 / \mathrm{kg}$ with $100 \%$ yield, the hydrogen can be sold for $\$ 1 / \mathrm{kg}$, and three $\mathrm{kg}$ carbon are produced for every $\mathrm{kg}$ hydrogen.

For the DAC numbers, we used data for the $\mathrm{CaO} / \mathrm{CaCO}_{3}$ absorption loop used by carbon engineering. ${ }^{79}$ Again, we assumed all energy in the process could be electrified with no change in cost (the reported methodology utilized natural gas for the calcining [desorption] step). We used energy intensity numbers assuming the $\mathrm{CO}_{2}$ is delivered at $0.1 \mathrm{MPa}$ and therefore not compressed, and CAPEX numbers for the $\mathrm{n}^{\text {th }}$ plant, as opposed to the first plant built.

Looking at the four chosen industries under fixed electricity prices at \$30/MWh gives a sense of the relative sizes of CAPEX, energy, OPEX, and profit margin (Figure 1). The y-axis is normalized to the market price per unit. OPEX is assumed to be $100 \%$ variable, and CAPEX is straight-line depreciated over 10 years with no salvage value and divided by the maximum annual unit output in order to put CAPEX on a per-unit basis. An ideal industrial participant who was not utilizing storage would have as large an energy cost per unit as possible to entice a producer to utilize only low-cost electricity, and as small a per-unit CAPEX as possible such that the cost penalty to participate would be minimized.

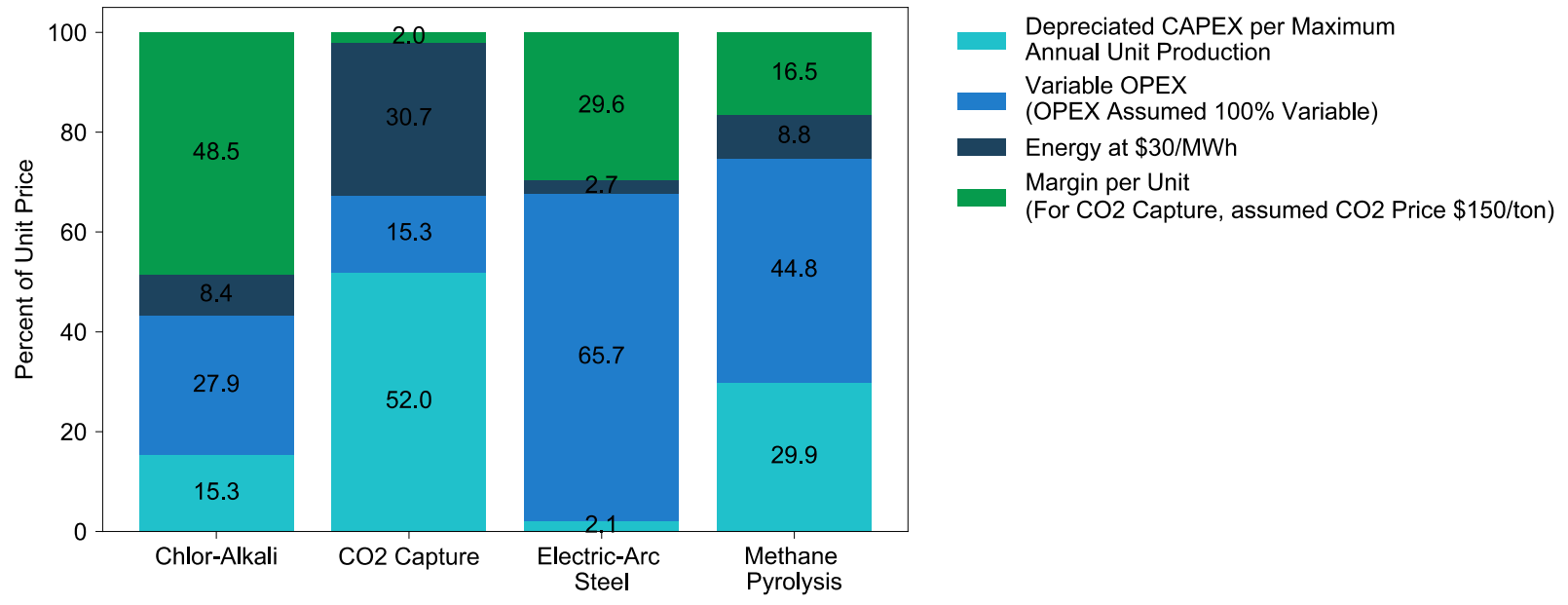

Figure 1. Production cost normalized to the unit selling price for each respective industry

1 ton ECU for Chlor-Alkali at average price from 2009-2017, $1 \mathrm{t}-\mathrm{CO}_{2}$ for atmospheric $\mathrm{CO}_{2}$ Capture $(\$ 150), 1$ ton of steel for Electric-Arc Steel at average price from 2014-2019, and $1 \mathrm{~kg} \mathrm{H} 2$ plus $3 \mathrm{~kg}$ solid carbon for Methane Pyrolysis. All OPEX is assumed to be $100 \%$ variable. All energy electrified and bought at a flat rate of $\$ 30 / \mathrm{MWh}$. CAPEX is straight-line depreciated over 10 years with no salvage value and normalized by the maximum annual unit product.

\subsection{Economic Feasibility of Negative Control Without Paired Storage}

We modeled participating in negative control without paired storage by reserving a portion of a plant's maximum operating capacity to remain idle during normal operation, such that capacity can be ramped up in times of surplus electricity production. Thus, we began by examining the net cost that plants in the four considered industries would endure in restricting manufacturing activity when electricity is not in oversupply.

To do so, we formulated a linear optimization problem to schedule optimal plant hourly electricity purchases and manufacturing decisions over the course of a year. We solved the 
optimization and calculated the corresponding profits for a baseline scenario and an idealized negative control scenario. The baseline scenario was modeled as a plant operating at $100 \%$ of nameplate capacity for $95 \%$ of the year and at $0 \%$ capacity for the remaining $5 \%$ of the year to account for downtime due to repairs. The negative control scenario modeled a plant operating at $70 \%$ (restricted) capacity during hours of the year with nonzero electricity prices (to allow for ramping capacity when needed), and at $100 \%$ capacity during any hour of the year when electricity prices were at $\$ 0$. Assuming that plants can run at full capacity during any $\$ 0$ electricity price hour is optimistic; it assumes that any hour with a $\$ 0$ electricity price is an hour in which electricity is being oversupplied, the quantity of oversupply has the necessary depth to sustain a plant running at full capacity during those times, and the plant can utilize $100 \%$ of its capacity during those hours - all of which are not necessarily true. Accordingly, this assumption models the minimum cost a plant would endure to participate at this level of negative control energy.

The profit-maximizing linear optimization problem can be formulated as maximizing the following objective function:

$$
\begin{gathered}
\text { Profit }_{y}=\max \sum_{h=1}^{8736} \text { Production }_{h} *\left(\text { Price }_{\text {product }}-\text { OPEX }_{\text {process }}\right)-\text { Price }_{\text {electricity }, h * \text { ProcessPower }_{h}[1]} \\
\text { where: } \\
\text { ProcessPower }_{h} \leq \text { EnergyIntensity }_{\text {per unit }} * \frac{\text { Plantsize }_{\text {process }}}{8760}[2]
\end{gathered}
$$

Price $_{\text {product, }}$ OPEX process, $_{\text {PlantSize }}$ process, and EnergyIntensity process are constants that vary with the process assessed and can be found in Table 1. Optimal electricity purchase and manufacturing decisions were made on an hourly timescale using ERCOT hourly day-ahead wholesale prices. We assumed that all modeled industrial loads can operate continuously, can adjust production levels at the granularity of 1 hour, and will stop purchasing electricity only if electricity costs are prohibitively high and diminish profits. All of the industrial processes considered except for EAF can operate continuously. EAF is a batch process, but can process roughly $1 \mathrm{batch} / \mathrm{hour},{ }^{83}$ which matches the granularity of control assumed in the linear program.

The hourly electricity price data used, Price electricity, $h$, was drawn from a set of future-looking (year 2050) hourly price duration curves for the ERCOT wholesale electricity market in a high variable renewable penetration scenario. ${ }^{84}$ The price duration curves were generated by Jadun et al., who used the Regional Energy Deployment System (ReEDS) capacity expansion model ${ }^{85}$ to estimate the evolution of the generator fleet with various levels of assumed willingness to pay for excess generation of electricity. The modeling methodology utilized in Jadun et al. assumed that market demand would raise electricity prices up to $\$ 0 / \mathrm{MWh}$; namely, that a sufficiently deep demand of electricity purchasers would always be willing to offtake excess generation for free. The resulting fleet was input into the PLEXOS ${ }^{86}$ production cost model to estimate hourly grid operation, including the locational marginal prices (LMPs) of electricity. This analysis used the generated LMPs associated with a region in the ERCOT West Load Zone. Around 36\% of the predicted electricity prices in the data set used were $\$ 0 / \mathrm{kWh}$, which means we modeled plants as running at $100 \%$ of nameplate capacity for around $36 \%$ of the year. We also compared our 
modeled price duration curve with the historical (2019) LMPs used later (See Figure A2-1 for details).

\subsection{Economic Feasibility of Negative Control With Paired Storage}

To estimate the economic feasibility of negative control for industrial plants with on-site battery storage, we modeled on-site Li-ion batteries using a linear optimization model to optimize battery NPVs for each industry over different years (2019 and 2050) and battery sizes. We calculated the NPV using the following procedure:

1. For each year in the battery lifespan:
A. Find the optimal electricity purchases and manufacturing decisions for the year
B. Calculate cash flow for the battery project as the cost savings accrued by utilizing the battery to arbitrage electricity purchases
C. Recalculate the battery energy capacity for the following year based on battery cycling behavior and capacity degradation.

2. Calculate the total NPV of battery cash flows from each year of the battery life.

We limited the scope of battery costs considered to only system capital and operating expenditures. For example, we did not consider the cost of installing extra transmission capacity for a factory as it is highly location-dependent, though it could be required to accommodate electricity needed to charge the battery. On the other hand, we also only considered the potential revenue from electricity price arbitrage when calculating battery NPV. As mentioned above, only considering revenue from price arbitrage likely underestimates battery value.

We drew the 2019 LMP data from the Judkins node in the ERCOT West Load Zone ${ }^{87}$ (a region currently with a fair amount of wind capacity) and used the same 2050 data set as described above. We assumed perfect foresight of electricity prices and use the same prices for each year of the battery lifespan. Numerous analyses of electricity price forecast impact on energy arbitrage profit have concluded that assuming perfect foresight overestimates resulting revenue by around $15 \%-20 \%$ as compared to simple but more realistic price forecast strategies. ${ }^{15}$

To optimally size batteries for each process, we calculated NPVs for a range of battery sizes and select the batteries that yield the highest NPV. We characterized batteries in terms of their energy (MWh) and power (MW) capacities. We measured energy capacity as the number of hours of full-intensity production that a battery can power after being fully charged and measured power capacity in terms of its C-rate. We tested every combination of energy capacities in $\{.2, .4, .6$, $\ldots, 8\}$ hours of production and power capacities from $\{.25, .5, .75,1\} \mathrm{C}$-rates. To account for energy capacity degradation, we assumed a battery storage temperature of $25^{\circ} \mathrm{C}$ and cycle lifetime of 6,000 cycles based on Samsung SDI estimates ${ }^{88}$ and approximate capacity

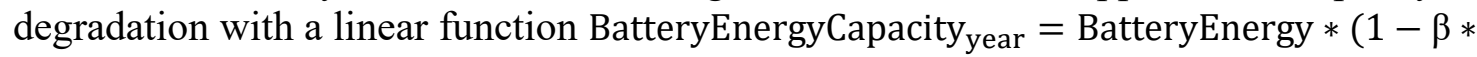
$\frac{\text { nCyclesElapsed }}{\text { batteryCycleLife }}$ ) (Equation 14) that updates battery capacity at the beginning of each new year.

The NPV optimization problem can be formulated as follows: 


$$
\begin{aligned}
& N P V \_ \text {max }=\max _{\begin{array}{c}
\text { BatteryEnergy, } \\
\text { BatteryPower }
\end{array}} \sum_{y=1}^{\text {batteryLife }} \frac{(1-\text { tax })\left(\text { Profit }_{\text {batt }, y}-\text { Profit }_{\text {noBatt }, y}-C A P E X_{\text {batt }} * C R F\right)+\text { tax } * \frac{C A P E X_{\text {batt }}}{\text { BatteryLife }}}{(1+\text { DiscountRate })^{y}}[3] \\
& \text { where: } \\
& \text { CAPEX } X_{\text {battery }}=\left(\text { projected } \frac{\$}{M W h}\right) * \text { BatteryEnergy }+\left(\text { projected } \frac{\$}{M W}\right) * \text { BatteryPower }[4] \\
& C R F=\text { Capital Recovery Factor }=\frac{\text { DiscountRate }}{1-(1+\text { DiscountRate })^{- \text {batteryLife }}}[5] \\
& \text { BatteryPower }=\text { ChargePower }_{\max }[6] \\
& \text { ChargePower }_{\text {max }}=\text { BatteryEnergyCapacity } * C_{\text {rate }}[7] \\
& \text { ProcessPower }_{\max }=\text { EnergyIntensity }_{\text {process }} * \frac{\text { PlantSize }_{\text {process }}}{8760}[8] \\
& C_{\text {rate }} \in[.25, .5, .75,1][9] \\
& \text { BatteryEnergy } \in[.2, .4, .6, \ldots, 8] * \text { ProcessPower }_{\max }[10]
\end{aligned}
$$

We used a tax rate of $21 \%$, corresponding to combined state and federal corporate taxes in Texas ${ }^{89}$ and a discount rate of $8.1 \%{ }^{22}$ BatteryLife is set to be 15 years based on Samsung SDI

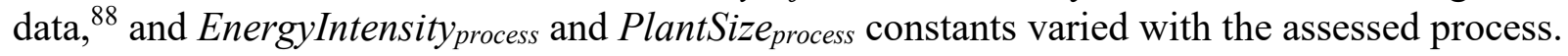
The projected battery capital costs $(\$ / \mathrm{MWh}$ and $\$ / \mathrm{MW})$ for 2019 and 2050 were drawn from the NREL 2020 Annual Technology Baseline. ${ }^{90}$ See Appendix for all constants used.

The profit resulting from scheduling optimal electricity purchases for each year can be formulated as maximizing the objective function for the no-battery case with additional constraints added for battery operation. For this calculation, we assumed that plants both with and without batteries are capable of operating at $100 \%$ of capacity at all times.

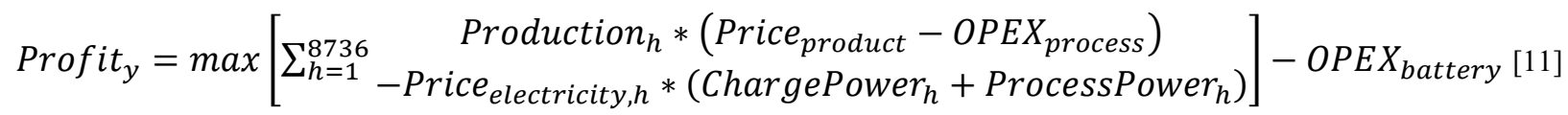

$$
\begin{aligned}
& \text { subject to the following constraints: } \\
& \text { EnergyStored }_{h}=(1-\alpha) \text { EnergyStored }_{h-1}+\eta \text { ChargePower }_{h}-\text { DischargePower }_{h}[12] \\
& \text { EnergyStored }_{h} \leq \text { BatteryEnergyCapacity year }_{\text {[13] }} \\
& \text { BatteryEnergyCapacity } \text { year }=\text { BatteryEnergy } *\left(1-\beta * \frac{\text { nCyclesElapsed }}{\text { batteryCycleLife }}\right)[14] \\
& \text { Production }_{h} * \text { energyIntensity }_{\text {process }}=\text { DischargePower }_{h}+\text { ProcessPower }_{h}[15]
\end{aligned}
$$




$$
\text { ProcessPower }_{h} \leq \text { ProcessPower }_{\text {max }}[16]
$$

$$
\text { ChargePower }_{\max }=\text { BatteryEnergyCapacity }_{\text {year }} * \text { Crate }_{2} \text { ChargePower }_{h}[17]
$$

DischargePower $_{\max }=\min \left(\right.$ ProcessPower $_{\max }$, ChargePower $\left._{\max }\right) \geq$ DischargePower $_{h}$

Profit ${ }_{n o B a t t, y}$ was assessed by setting the yearly battery energy capacity to 0 . Price product, $_{\text {, }}$ $O P E X_{\text {process, }}$, and EnergyIntensity process constants vary with the process assessed. OPEX $X_{\text {battery }}$ values for 2019 and 2050 again were drawn from the NREL 2020 Annual Technology Baseline. ${ }^{90}$ BatteryCycleLife was set to 6,000 cycles and $\beta$, the battery end-of-life energy capacity degradation, was set to .2 based on Samsung SDI data. ${ }^{88} \alpha$, battery self-discharge, was $2 \%$ of capacity/month, ${ }^{39}$ and $\eta$, the battery roundtrip efficiency, was set to $.9 .^{22}$ All constants in this calculation can also be found in the Appendix. 


\section{Results and Discussion}

\subsection{Economic Feasibility of Negative Control Without Paired Storage}

We found that without additional incentives, the considered industries would experience large losses from participating in negative control energy as modeled (Table 2). Therefore, utilities would have to pay prohibitively high compensations to make up for revenue lost from participating in our modeled form of negative control, and because these values are on a perplant basis, it does not appear the industries considered are a suitable target for negative control energy.

Table 2. Modeled NPV Changes in Adopting Negative Control Strategies vs. No Negative Control

\begin{tabular}{ll}
\hline Industry & $\begin{array}{l}\text { NPV } \\
\text { Impact } \\
(\$ M M)\end{array}$ \\
\hline Chlor-alkali & $-\$ 19$ \\
EAF & $-\$ 57$ \\
Methane pyrolysis & $-\$ 0.49$ \\
DAC & $-\$ 14$ \\
\hline
\end{tabular}

\subsection{Economic Feasibility of Negative Control With Paired Storage}

We examined calculated NPVs for optimally-sized batteries both in the present (2019) and future (2050). For 2050, we calculated NPVs for low, medium and high battery price projections ${ }^{90}$ (see Table A1- 3 for projected battery costs). Optimal NPVs were negative across all industries using 2019 electricity and battery prices (Table 3 ), yet became meaningfully positive for 2050 across both medium and low battery cost projections. See Table A4- 1 for the optimal battery sizes found under the 2050 medium and 2050 low battery price scenarios; for scenarios with negative NPVs, the optimal battery size is no battery.

Table 3. Optimal NPVs in Millions of Dollars Across Years and Battery Prices

\begin{tabular}{lllll}
\hline & $\mathbf{2 0 1 9}$ & $\mathbf{2 0 5 0}$ High & $\begin{array}{c}\mathbf{2 0 5 0} \\
\text { Medium }\end{array}$ & 2050 Low \\
\hline Chlor-alkali & $-\$ 1.9$ & $-\$ 0.5$ & $\$ 2.6$ & $\$ 17.5$ \\
\hline EAF & $-\$ 4.0$ & $-\$ 0.8$ & $\$ 11.6$ & $\$ 45.2$ \\
Methane pyrolysis & $-\$ 0.04$ & $\$ 0.0$ & $\$ 0.1$ & $\$ 0.4$ \\
\hline DAC & $-\$ 8.1$ & $-\$ 2.4$ & $-\$ 0.5$ & $\$ 35.6$
\end{tabular}

Optimal battery MWh and MW capacities ranged from 5.1MWh/1.3 MW to 876.1 MWh/219 MW, which, while large, are on the scale of battery systems being built today. ${ }^{91 *}$ We calculated NPVs for battery systems as large as $\$ 45$ million (See Appendix). We further assessed the

\footnotetext{
${ }^{*}$ We note that the physical footprint of the battery may be a hindrance in specific land-constrained locations. However, we did not include this facet in our analysis.
} 
sensitivity of the estimated NPVs to projected battery $\mathrm{kWh}$ and $\mathrm{kW}$ prices (Figure 2). For both 2019 and 2050, we assessed optimal operational profits when pairing processes with a battery that provides 5.0 hours of production for the respective industry and a power capacity of $.25^{\circ} \mathrm{C}$ : the optimal battery parameters found under the 2050 low battery cost scenario for all industries. We then varied the $\mathrm{kWh}$ and $\mathrm{kW}$ prices for the batteries, and calculated the total profit brought in by the battery after subtracting the corresponding capital expenditure. As can be seen, battery prices less than $\$ 110-130 / \mathrm{kWh}$ and upwards of $\$ 250 / \mathrm{kW}$ produce positive NPVs across all industries analyzed, with most industries able to profit at battery prices as high as $\$ 150 / \mathrm{kWh}$ installed. Therefore, if battery prices can continue to fall along the learning curve of the last decade $^{92}$, and electricity rate structures incorporate additional dynamism, this analysis suggests that behind-the-meter batteries for industrial customers could become profitable long before 2050 . 

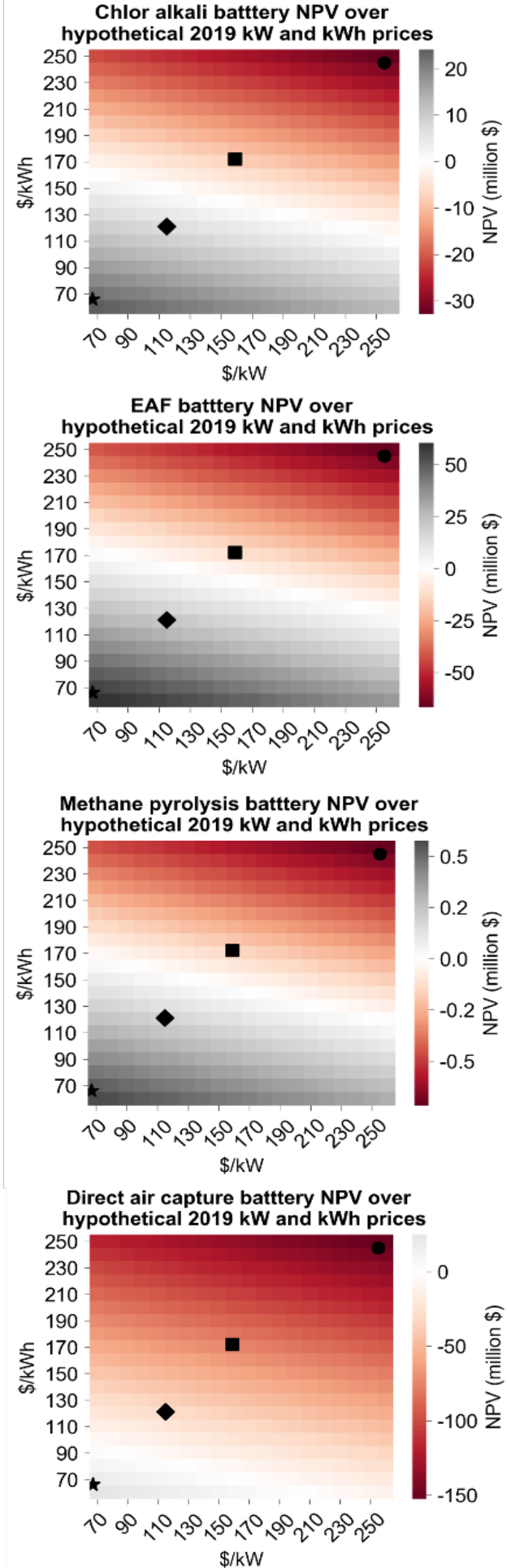
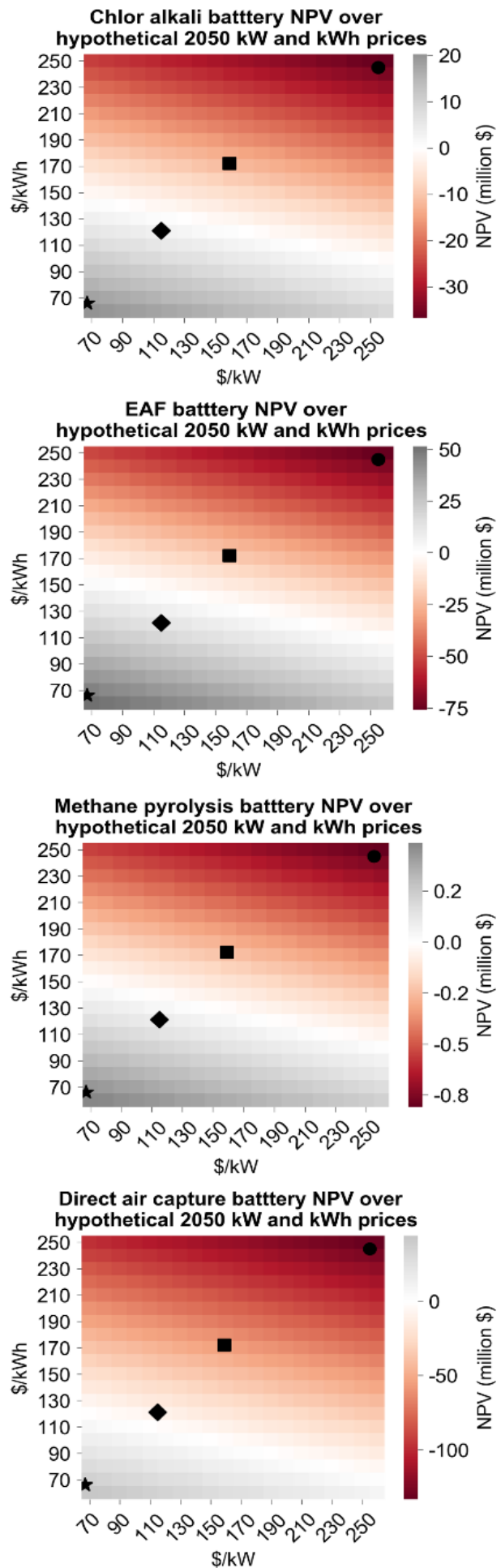

Figure 2. Battery NPV sensitivities to projected battery costs

The four considered industries are represented in 2019 (left) and 2050 (right). The four markers on each plot represent: (circle) 2019 battery costs, (square) projected 2050 high battery costs, (diamond) projected 2050 medium battery costs, and (star) projected 2050 low battery costs, according to the NREL Annual Technology Baseline 2020 report. 
We conservatively estimated the payback periods needed to recoup battery costs under the 2050 low battery cost scenario by finding the minimum number of years until the discounted, accumulated battery cashflows equal or exceed the total battery capital cost. By this method, battery savings will break even in 8 years for chlor-alkali, 7 years for EAF, 7 years for methane pyrolysis, and 10 years for DAC. We also estimated the internal rate of return for the battery under the 2050 low battery cost scenario by finding the discount rate at which the NPV becomes zero. Internal rates of return were equal to $15.2 \%$ for chlor-alkali, $16.7 \%$ for EAF, $15.8 \%$ for methane pyrolysis, and $11.7 \%$ for DAC.

We further examined the modeled optimal behavior of the processes with and without storage for individual years in the modeled battery lifetime. In Figure 3, we show load profiles for the first year of operation for the chlor-alkali process in the 2050 low battery cost scenario when paired with an optimally sized battery (280.5 MWh, 70.1 MW) versus operation with no battery. We can see the process drew a near-constant load without a paired battery. However, with a battery, the process varied its load to minimize the average electricity price bought from the grid. Figure $3 \mathrm{~b}$ shows the first 100 hours of operation to illustrate the arbitrage behavior in closer detail. 
2050 load profiles for chlor alkali, low battery cost scenario
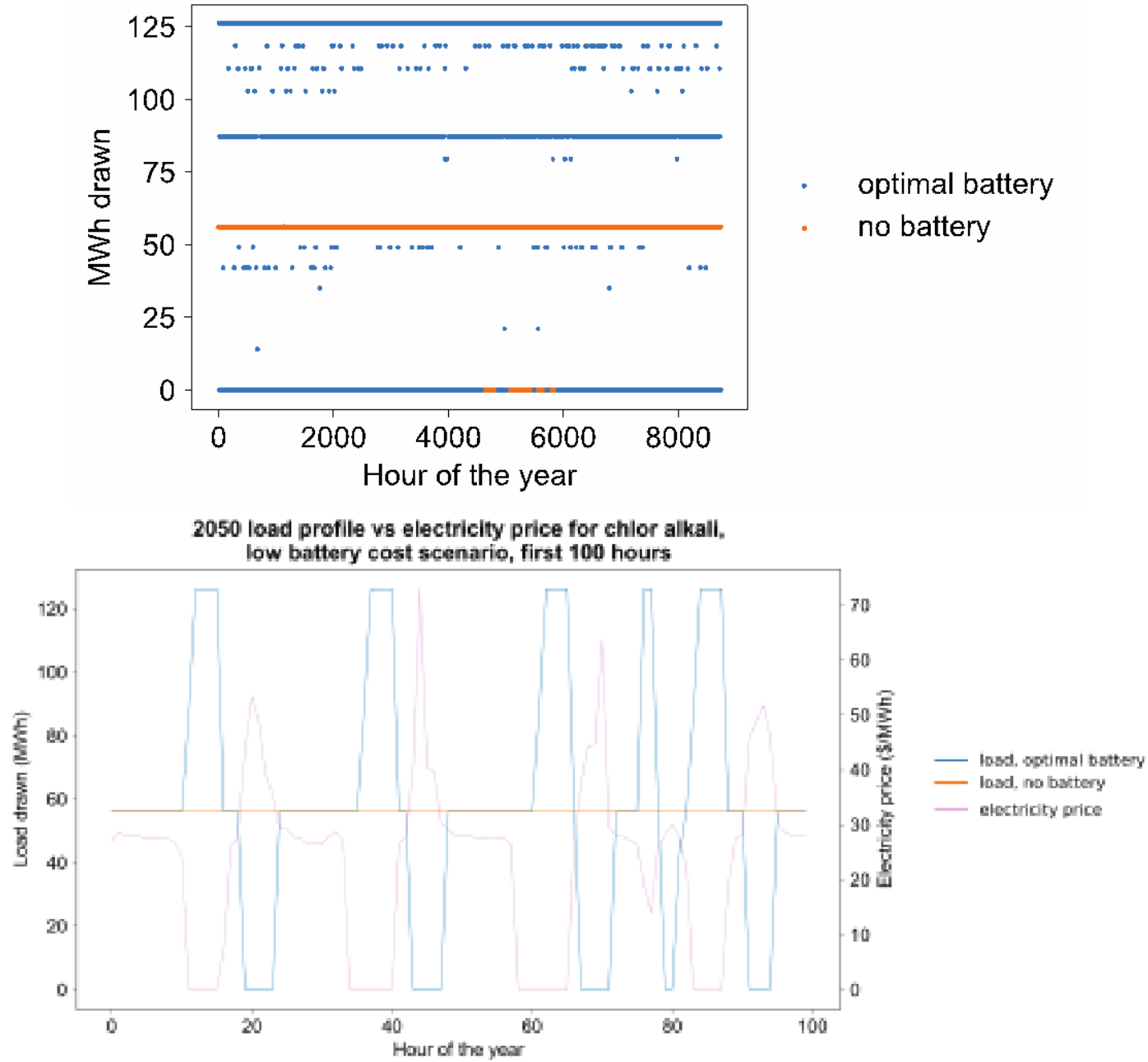

Figure 3. Load profiles chlor-alkali process with no battery vs. a paired optimally sized battery

Top: Entire first year of operation; bottom: Zoom-in of the first 100 hours of operation.

We further examined the impact of the battery on electricity purchasing and manufacturing behavior for the considered industries (Table 3). When batteries are being charged, plants with paired batteries in all industries showed increased negative control energy potential: for $29 \%$ of the year, their loads were higher than their maximum possible load with no paired battery. Chloralkali, EAF, and DAC also stopped pulling loads from the grid when electricity prices spiked (roughly $20 \%$ of the year), demonstrating positive control energy potential.

All industries saw an electricity cost savings of around $47 \%$ when using batteries that are optimally sized for the respective industry. Accordingly, these savings increased the profit margins of the plants by the following amounts, averaged across the 15 -year lifetime of the battery: Chlor-alkali $2.91 \%$, EAF $2.19 \%$, methane pyrolysis $2.96 \%$, and DAC by $16.2 \%$. This 
may be especially impactful for developing industries such as DAC as they seek to increase profitability or enable prolific use of captured carbon.

Table 4. Comparisons of First-Year Behavior When Pairing the Considered Process With an Optimally Sized Battery

\begin{tabular}{llccccc}
\hline & $\begin{array}{c}\text { Total } \\
\text { Electricity } \\
\text { Cost } \\
\mathbf{( \$ M M )}\end{array}$ & $\begin{array}{c}\text { Total \# } \\
\text { Units }\end{array}$ & $\begin{array}{c}\text { \# of \$0 } \\
\mathbf{M W h} \\
\text { Bought }\end{array}$ & $\begin{array}{c}\text { \# } \\
\text { Nonzero } \\
\text { Load } \\
\text { Hours }\end{array}$ & $\begin{array}{c}\text { Avg. } \\
\text { MW Per } \\
\text { Load } \\
\text { Hour }\end{array}$ & $\begin{array}{c}\text { Profit } \\
\text { Margin }\end{array}$ \\
\hline Chlor-alkali, NB & 9.59 & $1.80 \times 10^{5}$ & $1.78 \times 10^{5}$ & 8,662 & 56.1 & 45.9 \\
\hline Chlor-alkali, w/ B & 5.12 & $1.82 \times 10^{5}$ & $2.95 \times 10^{5}$ & 6,995 & 71.9 & 46.7 \\
\hline EAF, NB & 21.5 & $1.98 \times 10^{6}$ & $3.98 \times 10^{5}$ & 8,662 & 126 & 23.5 \\
\hline EAF, w/ B & 11.5 & $1.99 \times 10^{6}$ & $6.61 \times 10^{5}$ & 6,995 & 161 & 23.7 \\
\hline Methane Pyrolysis, NB & 0.22 & $6.86 \times 10^{5}$ & $4.04 \times 10^{3}$ & 8,662 & 1.27 & 35.9 \\
\hline Methane Pyrolysis, w/ B & 0.12 & $6.92 \times 10^{5}$ & $6.71 \times 10^{3}$ & 8,662 & 1.32 & 36.6 \\
\hline DAC, NB & 30.0 & $9.89 \times 10^{5}$ & $5.55 \times 10^{5}$ & 8,662 & 175 & 9.5 \\
\hline DAC, w/ B & 16.0 & $9.97 \times 10^{5}$ & $9.23 \times 10^{5}$ & 6,995 & 225 & 12.4
\end{tabular}




\section{Conclusions}

Our analysis shows that without storage, for the industries and scenarios analyzed here, capitalintensive industrial energy consumption cannot profitably act as negative control energy to stabilize the electricity grid. Conversely, our analysis using projected Li-ion battery costs and electricity prices suggests that large behind-the-meter batteries can show positive NPVs in the tens of millions of dollars per industrial facility by 2050 . This analysis only accounts for the lower overall electricity bill enabled by battery arbitrage and does not include what some have posited to be the more profitable aspects of large energy storage, particularly capacity deferral. ${ }^{22}$ The battery energy and power characteristics required to achieve optimal NPVs are technically achievable, as they are of similar scale to battery systems being constructed today. ${ }^{91}$

Our analysis finds that batteries profitably transform the considered industrial processes from constant to responsive loads, with more hours of electrical self-sufficiency. Large-scale batteries further benefit the grid in a number of ways: reducing the total amount of renewable capacity that needs to be built, ${ }^{17}$ reducing grid congestion, ${ }^{47}$ and providing quick ramping and stabilization capacity that will be needed as more renewable generation resources come online. ${ }^{3}$

Future studies could improve upon some current modeling assumptions. They could create an endogenous model that does not take electricity price as static, but accounts for feedback between shifted load and electricity price. This model could also attempt to understand the economics for late storage adopters, once storage represents a significant fraction of the grid, to estimate the point at which it becomes economically infeasible for industry to install additional energy storage. This analysis could also help with characterizing the risk of constructing the analyzed battery systems, which need 7-10 years to recoup capital outlays in the current model. To improve the accuracy of the model, a series of electricity prices spanning the lifetime of the battery could be generated and used in the analysis, and NPVs could be calculated using an imperfect electricity price forecast. This work suggests, however, that industrial manufacturers can in the future increase their load flexibility by profitably incorporating energy storage on-site, providing myriad grid services while improving the bottom line of the manufacturer. 


\section{References}

1. Augustine, C. Renewable Electricity Futures Study. Volume 2: Renewable Electricity Generation and Storage Technologies. 370.

2. Renewable Power Generation Costs in 2019. publications/2020/Jun/Renewable-PowerCosts-in-2019.

3. Kroposki, B. et al. Achieving a 100\% Renewable Grid: Operating Electric Power Systems with Extremely High Levels of Variable Renewable Energy. IEEE Power and Energy Magazine 15, 61-73 (2017).

4. Denholm, P. \& Hand, M. Grid flexibility and storage required to achieve very high penetration of variable renewable electricity. Energy Policy 39, 1817-1830 (2011).

5. Fleiter, T. A methodology for bottom-up modelling of energy transitions in the industry sector_ The FORECAST model. Energy Strategy Reviews 18 (2018).

6. Paulus, M. The potential of demand-side management in energy-intensive industries for electricity markets in Germany. Applied Energy 10 (2011).

7. Friedmann, S. J., Fan, Z. \& Tang, K. Low-Carbon Heat Solutions For Heavy Industry: Sources, Options, And Costs Today. (2019).

8. Rissman, J. Technologies and policies to decarbonize global industry_Review and assessment of mitigation drivers through 2070. Applied Energy 34 (2020).

9. Global Energy Transformation: A Roadmap to 2050. (2019).

10. World Energy Outlook 2019. (2019).

11. Lechtenböhmer, S., Nilsson, L. J., Åhman, M. \& Schneider, C. Decarbonising the energy intensive basic materials industry through electrification-Implications for future EU electricity demand. Energy 115, 1623-1631 (2016).

12. Shoreh, M. H., Siano, P., Shafie-khah, M., Loia, V. \& Catalão, J. P. S. A survey of industrial applications of Demand Response. Electric Power Systems Research 141, 31-49 (2016).

13. Lund, P. D., Lindgren, J., Mikkola, J. \& Salpakari, J. Review of energy system flexibility measures to enable high levels of variable renewable electricity. Renewable and Sustainable Energy Reviews 45, 785-807 (2015).

14. Houghton, B., Salovaara, J. \& Tai, H. Solving the rate puzzle: The future of electricity rate design. 7 https://www.mckinsey.com/industries/electric-power-and-natural-gas/ourinsights/solving-the-rate-puzzle-the-future-of-electricity-rate-design.

15. Zucker, A. et al. Assessing storage value in electricity markets: a literature review. (Publications Office of the European Union, 2013). 
16. Nykvist, B. \& Nilsson, M. Rapidly falling costs of battery packs for electric vehicles. Nature Climate Change 5, 329-332 (2015).

17. Wilson, M. Lazard's Levelized Cost of Storage Analysis-Version 4.0. 47.

18. Peskoe, A. The Case Against Direct FERC Regulation of Distributed Energy Resources. Harvard Law School: Environmental and Energy Law Program 20 (2018).

19. Wattles, P. Wholesale Storage Load: KTC-8. (2019).

20. Becerra, X. et al. Brief of Massachuesetts, California, District of Columbia, Michigan, and Rhode Island as Amici Curiae in Support of Respondent.

21. Eyer, J. \& Corey, G. Energy Storage for the Electricity Grid: Benefits and Market Potential Assessment Guide. 232.

22. Mallapragada, D. S., Sepulveda, N. A. \& Jenkins, J. D. Long-run system value of battery energy storage in future grids with increasing wind and solar generation. Applied Energy 275, $115390(2020)$.

23. Byrne, R. H. Estimating the Maximum Potential Revenue for Grid Connected Electricity Storage: Arbitrage and Regulation. 65.

24. Jenkin, T., Beiter, P. \& Margolis, R. Capacity Payments in Restructured Markets under Low and High Penetration Levels of Renewable Energy. Renewable Energy 46 (2016).

25. Ela, E. et al. Future Electricity Markets: Designing for Massive Amounts of ZeroVariable-Cost Renewable Resources. IEEE Power and Energy Magazine 17, 58-66 (2019).

26. Fisher, M. J. \& Apt, J. Emissions and Economics of Behind-the-Meter Electricity Storage. Environ. Sci. Technol. 51, 1094-1101 (2017).

27. Chlistunoff, J. Advanced chlor-alkali technology. 100.

28. Wang, X., Teichgraeber, H., Palazoglu, A. \& El-Farra, N. H. An economic receding horizon optimization approach for energy management in the chlor-alkali process with hybrid renewable energy generation. Journal of Process Control 24, 1318-1327 (2014).

29. Stubbles, J. R. The Minimill Story. Metall and Materi Trans B 40, 134-144 (2009).

30. Stubbles, J. Energy use in the U.S. steel industry: An historical perspective and future opportunities. (2000) doi:10.2172/1216250.

31. Dagle, R. A. et al. An Overview of Natural Gas Conversion Technologies for CoProduction of Hydrogen and Value-Added Solid Carbon Products. (2017) doi:10.2172/1411934.

32. Gasser, T., Guivarch, C., Tachiiri, K., Jones, C. D. \& Ciais, P. Negative emissions physically needed to keep global warming below $2{ }^{\circ} \mathrm{C}$. Nature Communications 6, 7958 (2015). 
33. National Academies of Sciences, Engineering \& Medicine. Negative Emissions Technologies and Reliable Sequestration: A Research Agenda. (The National Academies Press, 2019). doi:10.17226/25259.

34. Fuss, S. et al. Negative emissions-Part 2: Costs, potentials and side effects. Environ. Res. Lett. 13, 063002 (2018).

35. Islam, M. M., Zhong, X., Xiong, H. \& Sun, Z. Optimal scheduling of manufacturing and onsite generation systems in over-generation mitigation oriented electricity demand response program. Computers \& Industrial Engineering 115, 381-388 (2018).

36. Otashu, J. I. \& Baldea, M. Demand response-oriented dynamic modeling and operational optimization of membrane-based chlor-alkali plants. Computers \& Chemical Engineering 121, 396-408 (2019).

37. Joo, J.-Y., Raghavan, S. \& Sun, Z. Integration of Sustainable Manufacturing Systems into Smart Grids with High Penetration of Renewable Energy Resources. in 2016 IEEE Green Technologies Conference (GreenTech) 12-17 (2016). doi:10.1109/GreenTech.2016.10.

38. Gils, H. C. Assessment of the theoretical demand response potential in Europe. Energy 67, 1-18 (2014).

39. Braeuer, F., Rominger, J., McKenna, R. \& Fichtner, W. Battery storage systems: An economic model-based analysis of parallel revenue streams and general implications for industry. Applied Energy 239, 1424-1440 (2019).

40. Paulus, M. \& Borggrefe, F. The potential of demand-side management in energyintensive industries for electricity markets in Germany. Applied Energy 88, 432-441 (2011).

41. Babu, C. A. \& Ashok, S. Peak Load Management in Electrolytic Process Industries. IEEE Transactions on Power Systems 23, 399-405 (2008).

42. Brée, L. C., Perrey, K., Bulan, A. \& Mitsos, A. Demand side management and operational mode switching in chlorine production. AIChE Journal 65, e16352 (2019).

43. Roh, K., Brée, L. C., Perrey, K., Bulan, A. \& Mitsos, A. Flexible operation of switchable chlor-alkali electrolysis for demand side management. Applied Energy 255, 113880 (2019).

44. Ashok, S. Peak-load management in steel plants. Applied Energy 83, 413-424 (2006).

45. Ashok, S. \& Banerjee, R. Load-management applications for the industrial sector. Applied Energy 66, 105-111 (2000).

46. Castro, P. M., Sun, L. \& Harjunkoski, I. Resource-Task Network Formulations for Industrial Demand Side Management of a Steel Plant. Ind. Eng. Chem. Res. 52, 13046-13058 (2013). 
47. Sioshansi, R., Denholm, P., Jenkin, T. \& Weiss, J. Estimating the value of electricity storage in PJM: Arbitrage and some welfare effects. Energy Economics 31, 269-277 (2009).

48. Wu, D., Kintner-Meyer, M., Yang, T. \& Balducci, P. Economic analysis and optimal sizing for behind-the-meter battery storage. in 2016 IEEE Power and Energy Society General Meeting (PESGM) 1-5 (2016). doi:10.1109/PESGM.2016.7741210.

49. Cutter, E., Haley, B., Hargreaves, J. \& Williams, J. Utility scale energy storage and the need for flexible capacity metrics. Applied Energy 124, 274-282 (2014).

50. Shcherbakova, A., Kleit, A. \& Cho, J. The value of energy storage in South Korea's electricity market: A Hotelling approach. Applied Energy 125, 93-102 (2014).

51. Drury, E., Denholm, P. \& Sioshansi, R. The value of compressed air energy storage in energy and reserve markets. Energy 36, 4959-4973 (2011).

52. Walawalkar, R., Apt, J. \& Mancini, R. Economics of electric energy storage for energy arbitrage and regulation in New York. Energy Policy 35, 2558-2568 (2007).

53. McConnell, D., Forcey, T. \& Sandiford, M. Estimating the value of electricity storage in an energy-only wholesale market. Applied Energy 159, 422-432 (2015).

54. Bradbury, K., Pratson, L. \& Patiño-Echeverri, D. Economic viability of energy storage systems based on price arbitrage potential in real-time U.S. electricity markets. Applied Energy 114, 512-519 (2014).

55. Das, T., Krishnan, V. \& McCalley, J. D. Assessing the benefits and economics of bulk energy storage technologies in the power grid. Applied Energy 139, 104-118 (2015).

56. Zafirakis, D. The Multiple Role of Energy Storage in the Industrial Sector: Evidence from a Greek Industrial Facility. Energy Procedia 8 (2014).

57. Brée, L. C. et al. Techno-Economic Comparison of Flexibility Options in Chlorine Production. Ind. Eng. Chem. Res. 59, 12186-12196 (2020).

58. Gholian, A., Mohsenian-Rad, H. \& Hua, Y. Optimal Industrial Load Control in Smart Grid. IEEE Transactions on Smart Grid 7, 2305-2316 (2016).

59. Lamont, A. D. Assessing the economic value and optimal structure of large-scale electricity storage. IEEE Transactions on Power Systems 28, 911-921 (2013).

60. de Sisternes, F. J., Jenkins, J. D. \& Botterud, A. The value of energy storage in decarbonizing the electricity sector. Applied Energy 175, 368-379 (2016).

61. Pudjianto, D., Aunedi, M., Djapic, P. \& Strbac, G. Whole-Systems Assessment of the Value of Energy Storage in Low-Carbon Electricity Systems. IEEE Transactions on Smart Grid 5, 1098-1109 (2014). 
62. Denholm, P., Jorgenson, J., Hummon, M., Jenkin, T. \& Palchak, D. The Value of Energy Storage for Grid Applications. Renewable Energy 45 (2013).

63. Wang, X. An economic receding horizon optimization approach for energy management in the chlor-alkali process with hybrid renewable energy generation. Journal of Process Control 10 (2014).

64. Chlistunoff, J. Advanced Chlor-Alkali Technology. (2005).

65. Chlorine-Sodium Hydroxide (Chlor-Alkali): Chemical Economics Handbook. https://ihsmarkit.com/products/chlorine-sodium-chemical-economics-handbook.html (2019).

66. Chlorine Industry: Basic and Diversified Chemicals Dashboard. (2019).

67. Zhang, X., Hug, G., Kolter, Z. \& Harjunkoski, I. Industrial demand response by steel plants with spinning reserve provision. in 2015 North American Power Symposium (NAPS) 1-6 (IEEE, 2015). doi:10.1109/NAPS.2015.7335115.

68. Shyamal, S. \& Swartz, C. L. E. Real-time energy management for electric arc furnace operation. Journal of Process Control 74, 50-62 (2019).

69. The Future of Hydrogen. International Energy Agency (2019).

70. Upham, D. C. et al. Catalytic molten metals for the direct conversion of methane to hydrogen and separable carbon. Science 358, 917-921 (2017).

71. Techno-Economic Analysis of Methane Pyrolysis in Molten Metals: Decarbonizing Natural Gas. Chem. Eng. Technol. 9 (2017).

72. Dagle, R. et al. R\&D Opportunities for the Development of Natural Gas Conversion Technologies for Co-Production of Hydrogen and Value-Added Solid Carbon Products. (2017).

73. OPEN+ Concrete and Methane Cohorts. https://arpae.energy.gov/sites/default/files/documents/files/OPEN_2018_Cohort_Concrete_Methane_FINA L.pdf (2018).

74. Das, S., Warren, J., West, D. \& Laboratory, O. R. N. Global Carbon Fiber Composites Supply Chain Competitiveness Analysis. Technical Report 116 (2016).

75. Masson-Delmotte, V. et al. Global Warming of 1.5C. (2018).

76. Negative emissions technologies and reliable sequestration: a research agenda. (The National Academies Press, 2019).

77. Fuss, S. et al. Negative emissions_-Part 2: Costs, potentials and side effects. Environmental Research Letters 13, 063002 (2018).

78. Gasser, T., Guivarch, C., Tachiiri, K., Jones, C. D. \& Ciais, P. Negative emissions physically needed to keep global warming below $2{ }^{\circ} \mathrm{C}$. NATURE COMMUNICATIONS 7 (2015). 
79. Keith, D. W., Holmes, G., St. Angelo, D. \& Heidel, K. A Process for Capturing CO2 from the Atmosphere. Joule 2, 1573-1594 (2018).

80. Occidental Chemical Corporation Announces Plan to Build Membrane Cell Chlor-Alkali Plant in TN. (2011).

81. How should steelmakers adapt at the dawn of the EAF mini-mill era in China? McKinsey and Company (2019).

82. U.S. Midwest Domestic Hot-Rolled Coil Steel Index Futures. (2019).

83. Hendel, I. \& Spiegel, Y. Small Steps for Workers, a Giant Leap for Productivity. American Economic Journal: Applied Economics 6, 73-90 (2014).

84. Ruth, M. F., Jadun, P. N. \& Cole, W. Potential Availability and Price of Low-Cost, Dispatch-Constrained Electricity. Forthcoming.

85. Cohen, S. et al. Regional Energy Deployment System (ReEDS) Model Documentation: Version 2018. Renewable Energy 135 (2019).

86. $\quad$ PLEXOS $^{\circledR}$ Simulation Software. (2019).

87. Market Prices. http://www.ercot.com/mktinfo/prices.

88. SAMSUNG SDI Co., Ltd. ESS Batteries by Samsung SDI. (2018).

89. Watson, G. Combined State and Federal Corporate Income Tax Rates in 2020. Tax

Foundation https://taxfoundation.org/state-corporate-taxes-corporate-profits/ (2020).

90. Cole, W. \& Frazier, A. W. Cost Projections for Utility-Scale Battery Storage: 2020 Update. Renewable Energy 21 (2020).

91. Spector, J. The Biggest Batteries Coming Soon to a Grid Near You. Greentech Media https://www.greentechmedia.com/articles/read/the-biggest-batteries-coming-soon-to-a-grid-nearyou (2019).

92. Kittner, N., Lill, F. \& Kammen, D. M. Energy storage deployment and innovation for the clean energy transition. NATURE ENERGY 6 (2017).

93. Annual Technology Baseline | NREL. https://atb.nrel.gov/. 


\section{Appendix A.}

\section{A.1 Constants Used in NPV Optimization}

Table A1- 1. NPV Financial Parameters

\begin{tabular}{ll}
\hline Constant & \multicolumn{1}{c}{ Value } \\
\hline Tax & 0.21 \\
discountRate & 0.081
\end{tabular}

Table A1- 2. Battery Technical Parameters

\begin{tabular}{ll}
\hline Constant & \multicolumn{1}{c}{ Value } \\
\hline batteryLife & 15 years \\
batteryCycleLife & 6,000 cycles \\
$\begin{array}{l}\beta \text { (battery end-of-life energy } \\
\text { capacity degradation) }\end{array}$ & 0.2 \\
$\alpha$ (battery self-discharge) & $\begin{array}{l}2 \% \\
\text { capacity/month }\end{array}$ \\
$\eta$ (battery round-trip efficiency) & 0.9 \\
\hline
\end{tabular}

Table A1- 3. Battery Cost Data ${ }^{93}$

\begin{tabular}{llll}
\hline Year and Price Scenario & \$/kWh & \$/kW & $\begin{array}{c}\text { Annual } \\
\text { OPEX (\$) }\end{array}$ \\
\hline 2019 & 317 & 276 & 38.6 \\
\hline 2050 low & 71 & 62 & 8.63 \\
\hline 2050 medium & 126 & 110 & 15.32 \\
\hline 2050 high & 177 & 154 & 21.55
\end{tabular}




\section{A.2 Electricity Data}

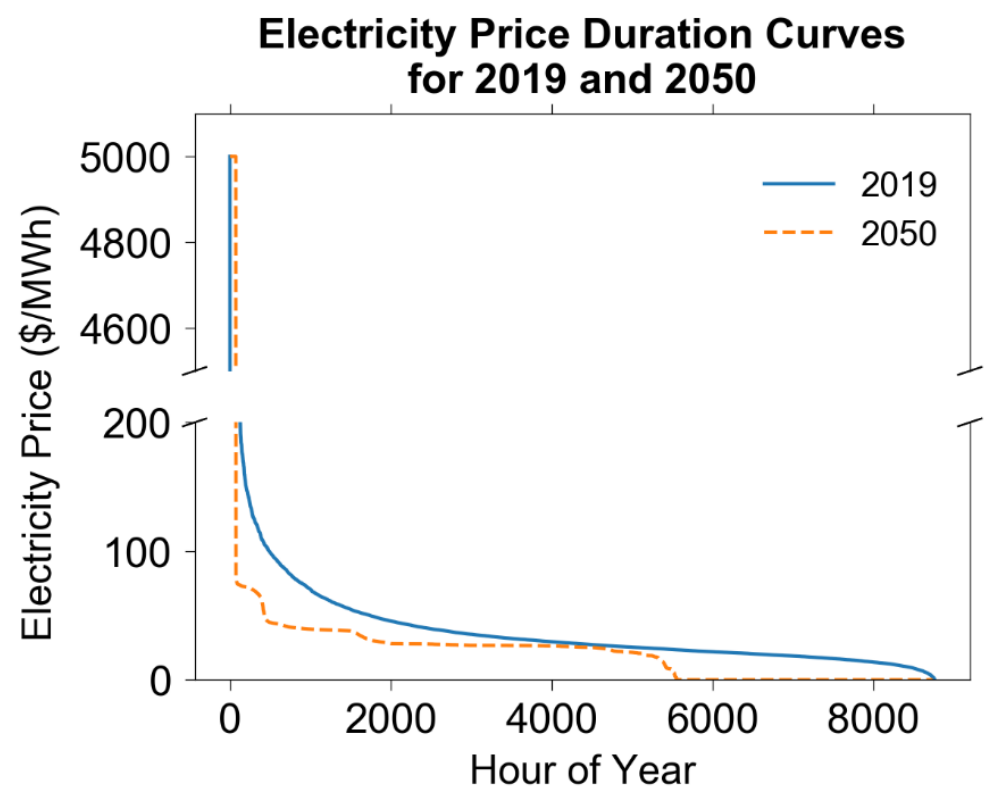

Figure A2- 1. Price duration curves for the electricity price data sets used (2019 and 2050)

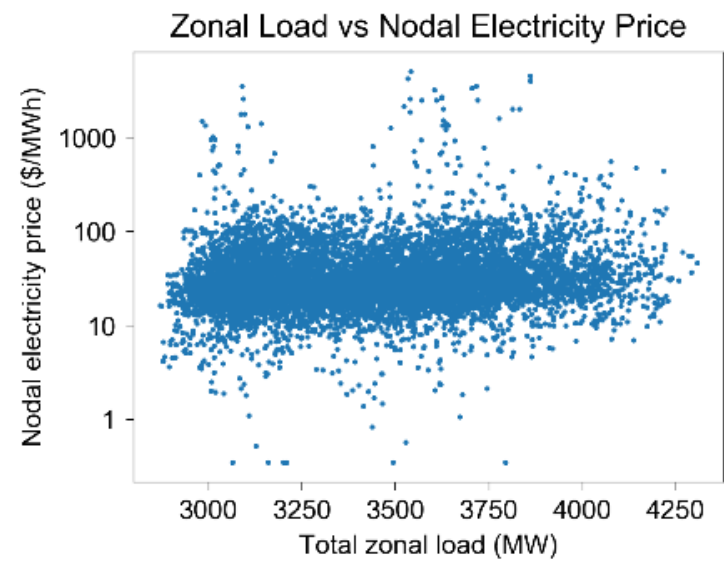

Figure A2- 2. Zonal load vs. nodal LMP for the Judkins node in ERCOT West Load Zone, 2019

Load and observed electricity price for the given region used are very weakly correlated. Calculated correlation coefficients: Pearson correlation coefficient of 0.046 ( $p$-value: $\left.1.5 \times 10^{-5}\right)$, Spearman correlation coefficient of $0.15(p-$ value: $6.5 \times 10^{-47}$ ), and Kendall rank correlation coefficient of 0.1 ( $p$ value: $2.4 \times 10^{-47}$ ).

\section{A.3 Calculation for Minimum Selling Cost (MSC)}

$M S C=O P E X_{\text {process }}+\frac{E_{\text {intensity }} * \text { Cost }_{\text {electricity, avg }}+C A P E X_{\text {plant,year }}+C A P E X_{\text {battery,year }}}{\text { unitsProduced }}$ 


\section{A.4 Optimal Battery Sizes Found for 2050 Low and Medium Battery Cost Scenarios}

Table A4- 1. Optimal Battery MWh and MW Capacities for 2050 Low and Medium Battery Cost

\begin{tabular}{lll}
\hline Industry/Price Scenario & \multicolumn{1}{c}{ Low } & \multicolumn{1}{c}{ Medium } \\
\hline \multirow{3}{*}{ Chlor-alkali } & 280.5 & 224.4 \\
& $\mathrm{MWh}, 70.1$ & $\mathrm{MWh}, 56.1$ \\
& $\mathrm{MW}$ & $\mathrm{MW}$ \\
$\mathrm{E}$ & 627.9 & 527.4 \\
& $\mathrm{MWh}, 157$ & $\mathrm{MWh}$, \\
& $\mathrm{MW}$ & $131.8 \mathrm{MW}$ \\
Methane pyrolysis & $6.4 \mathrm{MWh}$, & $5.1 \mathrm{MWh}$, \\
& $1.6 \mathrm{MW}$ & $1.3 \mathrm{MW}$ \\
\multirow{3}{*}{ DAC } & 876.1 & $0 \mathrm{MWh}$, \\
& $\mathrm{MWh}$, & OMW \\
& $219.0 \mathrm{MW}$ & \\
\hline
\end{tabular}


chlor alkali: NPVs across battery energy and power capacities;

2050 low battery price scenario $1 \mathrm{e} 7$

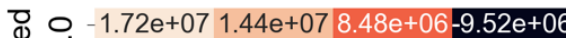

후 $1.73 \mathrm{e}+07 \quad 1.46 \mathrm{e}+07 \quad 8.86 \mathrm{e}+06-8.53 \mathrm{e}+06$

$\begin{array}{llll}\text { is } & 0-1.74 \mathrm{e}+07 & 1.47 \mathrm{e}+07 & 9.23 \mathrm{e}+06-7.56 \mathrm{e}+06\end{array}$

¿े $1.74 \mathrm{e}+07 \quad 1.49 \mathrm{e}+07 \quad 9.58 \mathrm{e}+06-6.6 \mathrm{e}+06$

o $\sim-1.74 e+07 \quad 1.5 e+07 \quad 9.92 e+06-5.66 e+06$

in $1.75 \mathrm{e}+071.51 \mathrm{e}+07 \quad 1.02 \mathrm{e}+07-4.77 \mathrm{e}+06$

की $-1.75 \mathrm{e}+07 \quad 1.51 \mathrm{e}+07 \quad 1.02 \mathrm{e}+07-4.77 \mathrm{e}+06$

نे $1.74 \mathrm{e}+071.52 \mathrm{e}+07 \quad 1.05 \mathrm{e}+07-3.87 \mathrm{e}+06$

¿ $\infty-1.74 \mathrm{e}+07 \quad 1.52 \mathrm{e}+07 \quad 1.05 \mathrm{e}+07-3.87 \mathrm{e}+06$

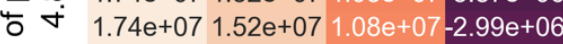

ஸ จ $-1.72 \mathrm{e}+071.53 \mathrm{e}+07 \quad 1.1 \mathrm{e}+07-2.17 \mathrm{e}+06$

○े $1.68 \mathrm{e}+07 \quad 1.52 \mathrm{e}+07 \quad 1.11 \mathrm{e}+07-1.43 \mathrm{e}+06$

\# $\bigcirc-1.62 \mathrm{e}+07 \quad 1.5 \mathrm{e}+07 \quad 1.12 \mathrm{e}+07-8.06 \mathrm{e}+05$

$25 \% \quad 33 \% \quad 50 \% \quad 100 \%$

$\%$ battery chargeable in one hour
1.5

1.0

0.5

0.0

$-0.5$
EAF: NPVs across battery energy and power capacities; 2050 low battery price scenario $1 \mathrm{e} 7$

이 우 $-4.47 \mathrm{e}+073.84 \mathrm{e}+072.51 \mathrm{e}+07-1.52 \mathrm{e}+07$

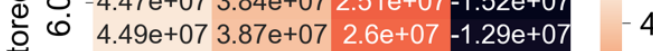

क $0-4.5 \mathrm{e}+07 \quad 3.91 \mathrm{e}+07 \quad 2.68 \mathrm{e}+07-1.08 \mathrm{e}+07$

ळ เ $4.51 \mathrm{e}+073.94 \mathrm{e}+072.76 \mathrm{e}+07-8.62 \mathrm{e}+06$

N $-4.52 e+073.97 e+072.83 e+07-6.53 e+06$

in $4.52 \mathrm{e}+073.99 \mathrm{e}+07 \quad 2.9 \mathrm{e}+07-4.54 \mathrm{e}+06$

की $0-4.52 \mathrm{e}+073.99 \mathrm{e}+07 \quad 2.9 \mathrm{e}+07-4.54 \mathrm{e}+06$

نं $4.52 \mathrm{e}+074.01 \mathrm{e}+072.97 \mathrm{e}+07-2.51 \mathrm{e}+06$

이 $\infty-4.52 e+074.01 e+07297 e+07-2.51 e+06$

¿ $\forall$ 4.5e+07 $4.03 e+07 \quad 3.03 e+07-5.7 e+05$

क จ $-4.45 \mathrm{e}+074.03 \mathrm{e}+073.07 \mathrm{e}+07 \quad 1.24 \mathrm{e}+06$

\begin{tabular}{l}
3 \\
\hline
\end{tabular}

\# $\bigcirc-4.2 e+07 \quad 3.96 e+07 \quad 3.09 e+07 \quad 4.14 e+06$

$25 \% \quad 33 \% \quad 50 \% \quad 100 \%$

$\%$ battery chargeable in one hour

methane pyrolysis: NPVs across battery energy and power capacities; 2050 low battery price scenario

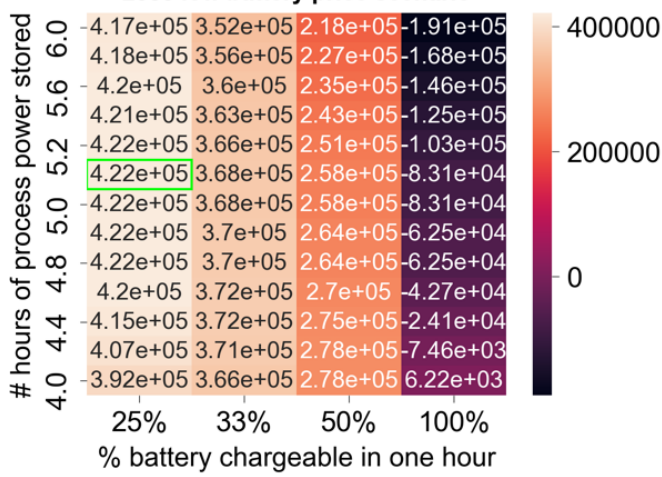

direct air capture: NPVs across battery energy and power capacities: 2050 low battery price scenario 1e7

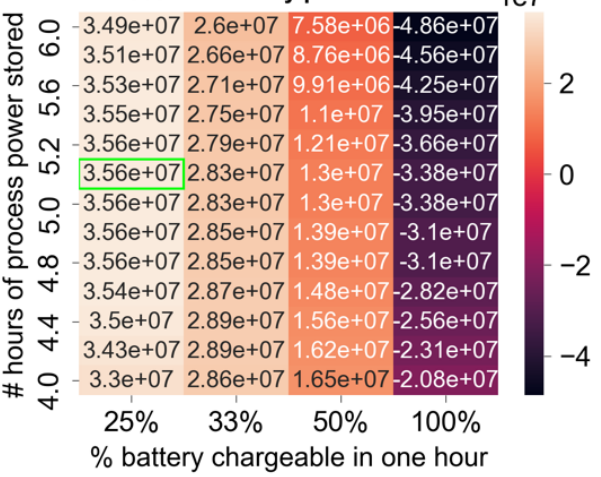

Figure A4- 1. NPVs across different battery energy and power capacities

a. Chlor-alkali, b. EAF, c. Methane pyrolysis, d. DAC in the 2050 low battery price scenario. Battery energy capacities are measured in terms of \# of hours of process power that the battery can support at full charge; battery power capacities are measured in terms of the \% of battery that can be charged in 1 hour. Optimal NPVs are highlighted in green. 
chlor alkali: NPVs across battery energy and power capacities; 2050 medium battery price scenario $1 \mathrm{e} 7$

D $5.0-4.14 \mathrm{e}+05-3.89 \mathrm{e}+06-1.27 \mathrm{e}+07-3.94 \mathrm{e}+07$

은 $4.8-1.08 \mathrm{e}+06-3.04 \mathrm{e}+06-1.15 \mathrm{e}+07-3.71 \mathrm{e}+07$

के $4.6-1.69 \mathrm{e}+06-2.22 \mathrm{e}+06-1.03 \mathrm{e}+07-3.48 \mathrm{e}+07$

z $4.4-2.18 \mathrm{e}+06-1.44 \mathrm{e}+06-9.14 \mathrm{e}+06-3.26 \mathrm{e}+07$

$4.2-2.51 \mathrm{e}+06-7.41 \mathrm{e}+05-8.09 \mathrm{e}+06-3.05 \mathrm{e}+07$

\& $4.0-2.59 \mathrm{e}+06-1.43 \mathrm{e}+05-7.15 \mathrm{e}+06-2.85 \mathrm{e}+07$
인 $3.8-2.46 \mathrm{e}+06$
$3.53 \mathrm{e}+05-6.32 \mathrm{e}+06-2.66 \mathrm{e}+07$

ㄴ. $3.6-2.33 \mathrm{e}+068.52 \mathrm{e}+05-5.47 \mathrm{e}+06-2.46 \mathrm{e}+07$

(c) $3.4-2.21 \mathrm{e}+06 \quad 1.3 \mathrm{e}+06-4.61 \mathrm{e}+06-2.27 \mathrm{e}+0$

วั $3.2-2.08 \mathrm{e}+06 \quad 1.6 \mathrm{e}+06-3.79 \mathrm{e}+06-2.08 \mathrm{e}+07$

\# $3.0-1.95 e+061.69 e+06-3.03 e+06-1.9 e+07$

$25 \% \quad 33 \% \quad 50 \% \quad 100 \%$

$\%$ battery chargeable in one hour

$-3$
EAF: NPVs across battery energy and power capacities; 2050 medium battery price scenario $1 \mathrm{e} 7$

D $5.0-7.07 \mathrm{e}+06-2.56 \mathrm{e}+06-2.22 \mathrm{e}+07-8.2 \mathrm{e}+07$

둔 $4.8-8.57 e+06-6.62 e+05-1.95 e+07-7.68 e+07-0$

$4.6-9.9 e+06 \quad 1.17 \mathrm{e}+06-1.69 \mathrm{e}+07-7.18 \mathrm{e}+07$

3. $4.4-1.09 e+072.88 e+06-1.44 e+07-6.69 e+07-2$

$4.2-1.16 \mathrm{e}+07 \quad 4.4 \mathrm{e}+06-1.21 \mathrm{e}+07-6.22 \mathrm{e}+07$

\& $4.0-1.15 e+075.64 e+06-1 e+07-5.78 e+07$

$3.8-1.1 e+076.63 e+06-8.31 e+06-5.36 e+07$

$3.6-1.04 \mathrm{e}+077.61 \mathrm{e}+06-6.55 \mathrm{e}+06-4.95 \mathrm{e}+07$

$3.4-9.81 e+068.46 e+06-4.76 e+06-4.53 e+0$

으 $3.2-9.23 e+068.96 e+06-3.07 e+06-4.12 e+07$

\# $3.0-8.65 \mathrm{e}+068.87 \mathrm{e}+06-1.55 \mathrm{e}+06-3.73 \mathrm{e}+07$

$25 \% \quad 33 \% \quad 50 \% \quad 100 \%$

$\%$ battery chargeable in one hour methane pyrolysis: NPVs across battery energy and power capacities; 2050 medium battery price scenario

\begin{tabular}{|c|c|}
\hline 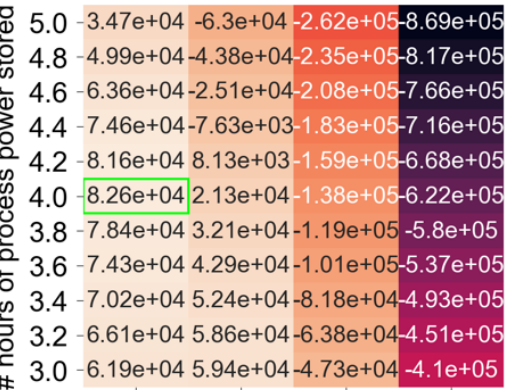 & $\begin{array}{l}-400000 \\
-600000 \\
-800000\end{array}$ \\
\hline $\begin{array}{cccc}25 \% & 33 \% & 50 \% & 100 \% \\
\% & \text { battery chargeable in one hour }\end{array}$ & \\
\hline
\end{tabular}

direct air capture: NPVs across battery energy and power capacities: 2050 medium battery price scenario $1 \mathrm{e} 7$

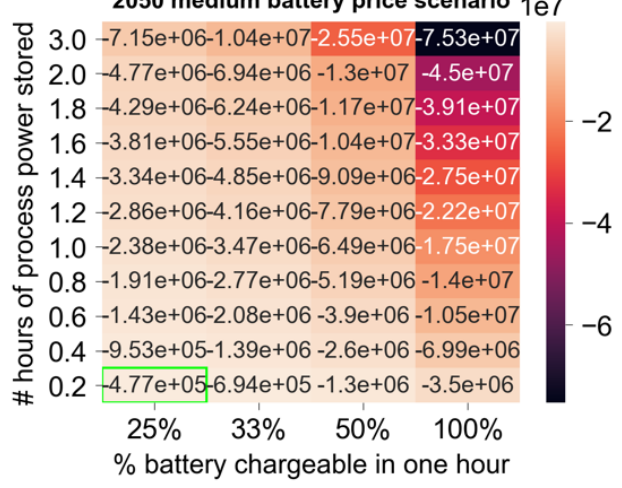

Figure A4- 2. NPVs across different battery energy and power capacities

a. Chlor-alkali, b. EAF, c. Methane pyrolysis, d. DAC in the 2050 medium battery price scenario. Battery energy capacities are measured in terms of \# of hours of process power that the battery can support at full charge; battery power capacities are measured in terms of the \% of battery that can be charged in 1 hour. Optimal NPVs are highlighted in green. 